Article

\title{
A Novel Electroactive Imide Oligomer and Its Application in Anticorrosion Coating
}

\author{
Bi-Sheng Huang ${ }^{1}$, Guan-Hui Lai ${ }^{1}$, Ta-I Yang ${ }^{2}$, Mei-Hui Tsai ${ }^{1,3, *}$ and Yi-Chen Chou ${ }^{4, *}$ \\ 1 Ph. D. Program, Graduate Institute of Precision Manufacturing, National Chin-Yi University of Technology, \\ Taichung 41170, Taiwan; unicorn6623917@gmail.com (B.-S.H.); hueilai123@gmail.com (G.-H.L.) \\ 2 Department of Chemical Engineering, Chung-Yuan Christian University, Taoyuan 330, Taiwan; \\ taiyang@cycu.edu.tw \\ 3 Department of Chemical and Materials Engineering, National Chin-Yi University of Technology, \\ Taichung 41170, Taiwan \\ 4 Department of Applied Cosmetology, Hungkuang University, Taichung 44302, Taiwan \\ * Correspondence: tsaimh@ncut.edu.tw (M.-H.T.); jacs1@hk.edu.tw (Y.-C.C.); Tel.: +886-4-23924505 (M.-H.T.)
}

Received: 13 November 2019; Accepted: 20 December 2019; Published: 4 January 2020

\begin{abstract}
A novel aniline tetramer (AT) capped electroactive imide oligomer (EIO) for metal corrosion protection was successfully synthesized in this study. The chemical structure of the EIO was characterized by liquid chromatography-mass spectrometry and Fourier-transform infrared spectroscopy. Furthermore, the redox behavior of EIO was identified using electrochemical cyclic voltammetry studies. An EIO coated on a cold-rolled steel (CRS) electrode was found to possess superior corrosion resistance to polyimide (PI) on a series of electrochemical corrosion measurements in $3.5 \mathrm{wt} . \% \mathrm{NaCl}$ solution over an extended period (30 days). The mechanism for the advanced corrosion protection of the PI coating on the CRS electrode could be attributed to the redox catalytic capabilities of the AT units present in the EIO. These capabilities may induce the formation of passive metal oxide layers on the CRS electrode. Scanning electron microscopy and X-ray photoelectron spectroscopy were used to analyze the surface condition of the CRS after the corrosion test. EIO- and PI-coated electrodes were identified by a series of electrochemical measurements, including corrosion potential $\left(\mathrm{E}_{\text {corr }}\right)$, polarization resistance $\left(\mathrm{R}_{\mathrm{p}}\right)$, and corrosion current $\left(\mathrm{I}_{\text {corr }}\right)$ measurements, along with electrochemical impedance spectroscopy (EIS).
\end{abstract}

Keywords: electroactive; aniline tetramer; anti-corrosion

\section{Introduction}

Metallic corrosion is a serious safety and economic issue for construction and industrial development [1]. Many approaches to corrosion protection have been developed, including organic coatings [2-5], inorganic coatings [6,7], ceramic coatings [8], and corrosion inhibitors [9,10]. Recently, organic coatings have attracted significant attention due to their potential for simple preparation, low cost, and functional potential, while being considered one of the most efficient strategies for corrosion protection. However, most of the organic coatings are not perfect barriers for providing long-term corrosion protection because such coatings are more or less permeable to corrosive media like water, oxygen, and ions. Therefore, several approaches for corrosion protection have been developed utilizing organic coatings. Some methods involve the addition of chromate as a corrosion inhibitor, which can provide the highest level of corrosion protection. Unfortunately, the adverse health and environmental effects, high toxicity, and carcinogenic risks of chromium limit its safety and therefore use [11,12].

Conducting polymers such as polyaniline (PANI), polypyrrole, and polythiophene are interesting materials for both research and technological applications. There has been increasing interest in the 
use of these polymers to reduce the corrosion of oxidizable metals [13-15]. Among these types of polymers, PANI has been considered one of the most promising electrode materials due to its facile synthesis, environmental stability, unique electronic properties, and simple acid-base doping/dedoping chemistry [16,17]. Although PANI has good anti-corrosion properties [18-20], poor solubility of PANI in common organic solvents has limited its practical application in many fields. To find an appropriate counter to this shortcoming, aniline oligomers and their derivatives have been the subject of much recent research [21-24].

Kaner and his research team have demonstrated that aniline tetramer (AT) is the smallest oligomer unit that can fully represent the structure of PANI [25]. Faul et al. synthesized the AT-alkyl diblock compound which self-assembled into single-crystalline two-dimensional microplates and studied its electrical conductivity [26]. Chao and Wang also prepared electroactive polymers containing AT in the main and side chains, which exhibited electrochemical properties, electrochromic behavior, and fluorescent sensing properties [27-29]. Huang et al. incorporated the amino-capped aniline trimer into a polyurethane prepolymer to obtain electroactive polyurethane coatings, exhibiting a stronger corrosion protection on the cold rolled steel in the corrosion medium than the pristine polyurethane coating [30]. Liu et al. prepared self-assembled AT based conducting nanofiber incorporated into a waterborne epoxy as a composite coating to enhance the corrosion resistance of mild steel (Q235 grade), demonstrating a relatively high conductivity and reversible redox behavior [31].

Polyimide (PI) is a high-performance engineering polymer with outstanding properties, including film-forming ability, thermal stability, and mechanical properties compared to conventional polymers. Thus, PI films have been used commercially in various applications such as flexible substrates, gas separation membranes [32], chemical sensors [33,34], and anticorrosion materials [5,35,36].

In this work, we present the electrochemically investigated corrosion protection properties of aniline tetramer-capped electroactive imide oligomer (EIO) coating on cold-rolled steel (CRS) electrodes. The corrosion resistance of the EIO coating was compared to a corresponding PI coating using a series of electrochemical measurements. The electroactivity of the EIO was characterized by cyclic voltammetry. The Tafel curve and EIS spectra were used to investigate the anti-corrosion performance. Scanning electron microscopy and X-ray photoelectron spectroscopy were used to analyze the corrosion products.

\section{Experimental}

\subsection{Materials and Instrumentation}

N-Phenyl-p-phenylenediamine (98\%, Alfa-Aesar, haverhill, MA), ferric chloride (99\%, ECHO, Taichung), 4-4'-diaminodiphenylether (ODA, 97\%, Sigma-Aldrich, Missouri, St. Louis), 4,4'-(4,4'-Isopropylidenediphenoxy)bis(phthalic anhydride) (IDPA, 98\%, Sigma-Aldrich, Missouri, St. Louis), N-methyl-2-pyrrolidone (NMP, 99\%, TEDIA, Fairfield, OH), hydrochloric acid (35\%, SHOWA, Xingtian city, Saitama), ammonium persulfate (APS, 98\%, J.T.Baker, Phillipsburg, New Jersey), ammonium hydroxide (25\%, SHOWA, Xingtian city, Saitama), N,N-Dimethylacetamide (DMAc, 99\%, TEDIA, Fairfield, OH), dimethylformamide (DMF, 99\%, TEDIA, Fairfield, OH), dimethyl sulfoxide (DMSO, 95\%, TEDIA, Fairfield, OH), tetrahydrofuran (THF, 99.5\%, Acros, Geel, Belgium), chloroform (99\%, Shimakyu's Pure Chemicals, Osaka-shi, Osaka), dichloromethane $(99.5 \%$, Shimakyu's Pure Chemicals, Osaka-shi, Osaka), acetone (99\%, ECHO, Taichung), ethanol (95\%, ECHO, Taichung) were used as received. Attenuated total reflection Fourier transform-infrared spectra were collected using an FTIR spectrometer (JASCO, Hachioji, Tokyo, FT/IR-4600) at room temperature, the resolution used in the measurements and the number of scans was $4 \mathrm{~cm}^{-1}$ and 64 scans, respectively. Mass spectra were obtained on a triple quadrupole mass spectrometer (TSQ Quantum) with an ESI source. UV-Vis absorption spectra were collected using a UV-Vis spectrometer (JASCO V-750). The field emission scanning electron microscope (JEOL, Akishima, Tokyo, JSM-7800F, in-lens Schottky field emission electron gun, accelerating voltages was $3.0 \mathrm{KV}$ ) and X-ray photoelectron spectrometer (XPS, Thermo $\mathrm{K}$-Alpha, Al K-alpha microfocus monochromated X-ray source) were used to characterize passivation 
by metal oxide layers. Cyclic voltammetry experiments were performed on $\mathrm{CHI}$ 6273E electrochemical analyzer using a conventional three-electrode system. The electrochemical corrosion measurements were performed using an electrochemical workstation zive sp1 (WonATech, Seoul, Korea). The area of work electrode was $1 \mathrm{~cm}^{2}$. All tests were performed at $25^{\circ} \mathrm{C}$ in corrosive medium $(3.5 \mathrm{wt}$ \% sodium chloride solution).

\subsection{Synthesis of Aniline Tetramer (AT)}

The synthesis of AT was performed by a modification of the published literature procedures [37]. The ferric chloride hexahydrate $(4.90 \mathrm{~g}, 0.01 \mathrm{~mole})$ in $\mathrm{HCl}$ solution $(30 \mathrm{~mL}, 1.0 \mathrm{M})$ was rapidly added to a solution of the $\mathrm{N}$-phenyl-1,4-phenylenediamine (aniline dimer, $2.0 \mathrm{~g}, 0.01 \mathrm{~mole}$ ) in $\mathrm{HCl}$ solution (200 mL, 1.0 M). After vigorous mechanical stirring for $4 \mathrm{~h}$ in the ice bath, the product was collected by centrifugation, and washed repeatedly with $1.0 \mathrm{M} \mathrm{HCl}$ and deionized water until the supernatant was colorless. The resulting precipitate in the emeraldine salt state was then treated with ammonium hydroxide solution $(1.0 \mathrm{M}, 200 \mathrm{~mL})$ for $24 \mathrm{~h}$. The precipitate was collected by filtration and dried in a vacuum oven at $50{ }^{\circ} \mathrm{C}$ for $24 \mathrm{~h}$ to yield aniline tetramer in the emeraldine base state.

\subsection{Synthesis of Polyimide (PI)}

A total of $1.04 \mathrm{~g}$ ( $2 \mathrm{mmol})$ IDPA was dissolved in $10 \mathrm{~mL}$ of NMP under nitrogen at room temperature, followed by slowly added into a stirred solution of $0.4 \mathrm{~g}$ ( $2 \mathrm{mmol})$ of ODA dissolved in $10 \mathrm{~mL}$ of NMP. The reaction mixture was stirred for $6 \mathrm{~h}$ to obtain a solution containing poly(amic acid) (PAA). The as-prepared PAA solution was dried under vacuum at $250{ }^{\circ} \mathrm{C}$ for $5 \mathrm{~h}$ to complete the chemical imidization reaction of the polyimide (PI).

\subsection{Synthesis of Electroactive Amic Acid Oligomer (EAAO) and Imide Oligomer (EIO)}

A total of $1.04 \mathrm{~g}$ ( $2 \mathrm{mmol})$ of IDPA was dissolved in $10 \mathrm{~mL}$ of NMP under nitrogen at room temperature, followed by slowly added into a stirred solution of $0.73 \mathrm{~g}$ ( $2 \mathrm{mmol})$ of AT dissolved in $10 \mathrm{~mL}$ of NMP. The solution was magnetically stirred for $4 \mathrm{~h}$ to obtain a solution containing aniline tetramer capped electroactive amic acid oligomer (EAAO). The as-prepared EPAAO solution was dried under vacuum at $250^{\circ} \mathrm{C}$ for $3 \mathrm{~h}$ to complete the chemical imidization reaction of the electroactive imide oligomer (EIO), as shown in Scheme 1.

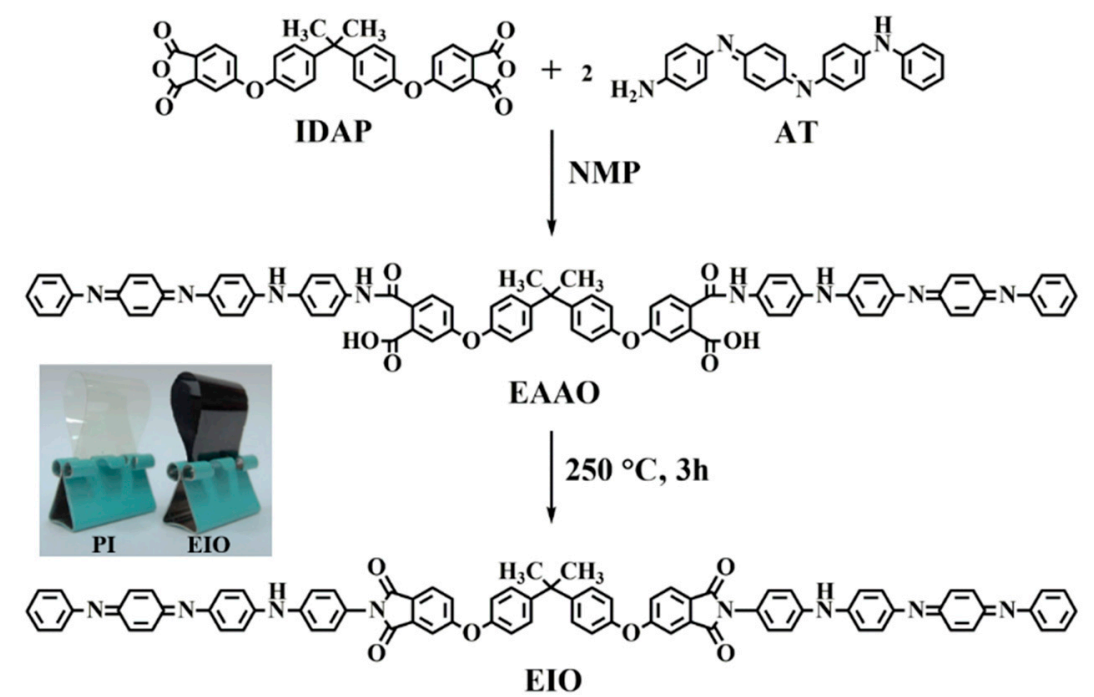

Scheme 1. Synthesis route of the EAAO and EIO. 


\subsection{Reduction of AT and EAAO}

The as-prepared EAAO solution was poured into $100 \mathrm{~mL}$ of distilled water for precipitation. The product was collected by filtration and washed with an excess of distilled water and dichloromethane several times, and finally dried under dynamic vacuum at room temperature for $24 \mathrm{~h}$. The as-prepared AT and EAAO $(0.1 \mathrm{~g})$ were dispersed into a solution of $1 \mathrm{~mL}$ hydrazine hydrate in $10 \mathrm{~mL} 1.0 \mathrm{M}$ ammonium hydroxide, respectively. After stirring for $24 \mathrm{~h}$, the products were filtered and washed with distilled water several times, and dried under dynamic vacuum at $40{ }^{\circ} \mathrm{C}$ for $24 \mathrm{~h}$. Finally, the obtained the leucoemeraldine oxidation state of AT and EAAO.

\subsection{Electrochemical Measurements}

All of the electrochemical corrosion measurements were performed by electrochemical workstation zive sp1 (Wonatech, Korea) at $25{ }^{\circ} \mathrm{C}$ in corrosive medium ( $3.5 \mathrm{wt} . \%$ sodium chloride solution). The working electrode (cold rolled steel, CRS) was groundby sandpaper 800 and 1000 grit, sequentially. Meanwhile, each of the AT, EAAO and PAA solutions were prepared with NMP and then drop-coating onto the groundCRS. The samples were dried under vacuum at $250{ }^{\circ} \mathrm{C}$ for $3 \mathrm{~h}$. The thickness of the coatings was determined using micrometers (Mitutoyo 293-240-30 IP65, range 0-25 mm, resolution $0.001 \mathrm{~mm}$ ). The average thickness was $0.022 \mathrm{~mm} \pm 0.001 \mathrm{~mm}$. The area of working electrode was $1 \mathrm{~cm}^{2}$. All tests were performed in the corrosive medium for one hour to ensure the steady state prior to polarization current measurement. The potential was scanned from -250 to $+250 \mathrm{mV}$ at a scan rate of $2.5 \mathrm{mV} \mathrm{s}^{-1}$ for polarization current experiments. The corrosion potential $\left(E_{\text {corr }}\right)$ and corrosion current density $\left(I_{\text {corr }}\right)$ were determined by the Tafel extrapolation method. The $I_{\text {corr }}$ was determined by superimposing a straight line along the linear portion of cathodic or anodic curve and then extrapolating it through $E_{\text {corr }}$.

The polarization resistance $\left(R_{p}\right)$ value was calculated from the Tafel plots, according to the Stearn-Geary equation [38,39]:

$$
R_{p}=\frac{b_{a} b_{c}}{2.303\left(b_{a}+b_{c}\right) I_{c o r r}}
$$

where $b_{a}$ and $b_{c}$ are the anodic slope and cathodic slope, respectively. Corrosion rate $(C R$, in mm per year) was calculated using the following equation [40,41]:

$$
\mathrm{CR}=\frac{I_{\text {corr }} \times M}{D \times V} \times 3270
$$

where $I_{\text {corr }}$ is the current density $\left(\mathrm{A} \mathrm{cm}^{-2}\right), M$ is the molecular mass, $V$ is the valence (the number of electrons that lose during the oxidation reaction), and $D$ is the density of CRS $\left(\mathrm{g} \mathrm{cm}^{-3}\right)$.

\section{Results and Discussion}

\subsection{Characterization of $A T$}

The Mass and ATR-FTIR spectra of AT as shown in Figure 1. The characterizations of AT were as follows: ion trap-MS m/z: $[\mathrm{M}+\mathrm{H}]^{+}$calculated for $\mathrm{C}_{24} \mathrm{H}_{20} \mathrm{~N}_{4}=365.4$. Found 365.4. In the ATR-FTIR spectrum of AT, the characteristic bands at $3314 \mathrm{~cm}^{-1}$ and $3208 \mathrm{~cm}^{-1}$ were attributed to the N-H stretching modes. Moreover, the characteristic bands at $1594 \mathrm{~cm}^{-1}$ and $1504 \mathrm{~cm}^{-1}$ were attributed to $\mathrm{C}$ $=\mathrm{C}$ of quinoid rings and benzenoid rings, respectively [37]. 

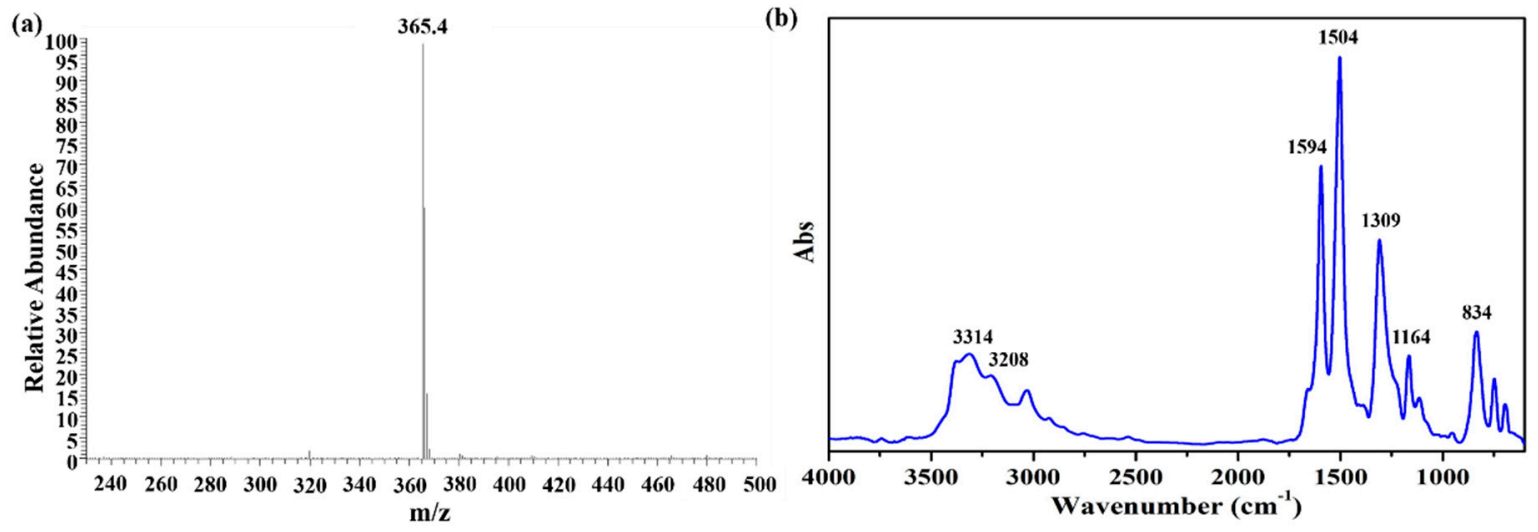

Figure 1. Characterization of aniline tetramer by (a) Mass and (b) ATR-FTIR spectroscopies.

\subsection{Characterization of $E A A O$ and $E I O$}

The as-prepared aniline tetramer-terminated EAAO and EIO were characterized by ATR-FTIR, as shown in Figure 2. In both of the ATR-FTIR spectra the characteristic band found at about $3259 \mathrm{~cm}^{-1}$ was attributed to the N-H stretching modes. Moreover, characteristic bands at $1580 \mathrm{~cm}^{-1}$ and $1506 \mathrm{~cm}^{-1}$ were attributed to $C=C$ of quinoid rings and benzenoid rings, respectively [42,43]. The ATR-FTIR spectrum of EAAO was shown in Figure 2a, the characteristic band at $1653 \mathrm{~cm}^{-1}$ was attributed to $\mathrm{C}=\mathrm{O}$ of $\mathrm{CONH}$. After thermal imidization, the characteristic bands of the carboxyl groups vanished in the EIO spectrum, as shown in Figure 2b. Meanwhile, new characteristic absorption bands appeared at $1774 \mathrm{~cm}^{-1}$ and $1715 \mathrm{~cm}^{-1}$ of the EIO spectrum, which may be associated with asymmetric and symmetric carbonyl stretching. Moreover, the characteristic band found at $1378 \mathrm{~cm}^{-1}$ and $746 \mathrm{~cm}^{-1}$ was designated as the C-N stretching and deformation of the imide groups, respectively [44,45]. The above information indicates that the EAAO had been effectively converted into the corresponding EIO through the thermal imidization process.

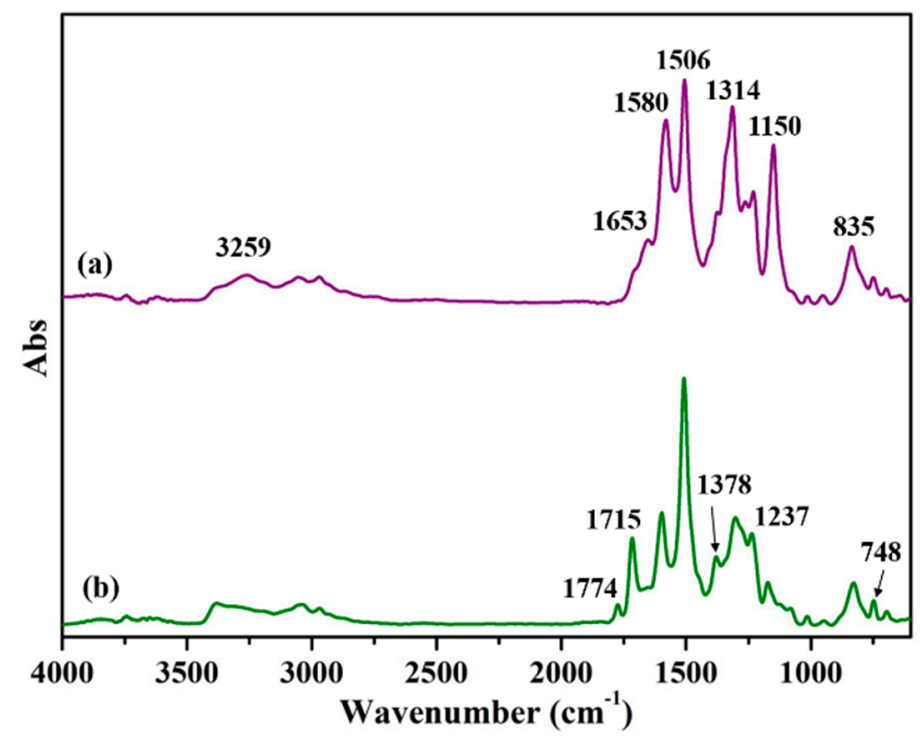

Figure 2. ATR-FTIR spectroscopies of (a) EAAO and (b) EIO.

The solubility of the synthesized electroactive amic acid oligomer in some common organic solvents is summarized in Table 1. The EAAO exhibited excellent solubility in many polar solvents such as NMP, DMF, DMAc, DMSO and THF. The high solubility of EAAO could be attributed to the following reasons: First, the flexible ether linkage (-O-) of IDPA, which reduced the rotation energy barrier of the molecule chain and secondly, the polar functional groups (carboxylic acid and amide) of 
EAAO, which enhanced the interaction between EAAO and the solvent [46]. The high solubility of the EAAO provides a distinct advantage in processing.

Table 1. Solubility of EAAO in common organic solvents ${ }^{\text {a }}$.

\begin{tabular}{cccccccccc}
\hline & NMP & DMF & DMAc & DMSO & THF & $\mathrm{CHCl}_{3}$ & $\mathrm{CH}_{2} \mathrm{Cl}_{2}$ & Acetone & Ethanol \\
\hline $\mathrm{EAAO}$ & ++ & ++ & ++ & ++ & ++ & + & + & + & + \\
\hline
\end{tabular}

a The solubility of the EAAO was determined with $5 \%$ solid content at $25^{\circ} \mathrm{C} .++=$ soluble, $+=$ partially soluble .

\subsection{Chemical Oxidation of $A T$ and $E A A O$}

The obtained LB state of AT and EAAO were dissolved in NMP and ethanol, respectively. Subsequently, a trace amount of $\left(\mathrm{NH}_{4}\right)_{2} \mathrm{~S}_{2} \mathrm{O}_{8}$ was added to them. The clear solution gradually changed dark blue and then purple upon oxidization. This process was continuously monitored by UV-Vis spectra, as shown in Figure 3. Initially, in each of the UV-Vis spectra, only one absorption band (AT at $326 \mathrm{~nm}$, EAAO at $316 \mathrm{~nm}$ ) was observed which is associated with the $\pi-\pi^{*}$ transition of the conjugated ring system [47]. When it is slowly oxidized, the absorption undergoes a blue shift (AT from $326 \mathrm{~nm}$ to $300 \mathrm{~nm}$, EAAO from $316 \mathrm{~nm}$ to $306 \mathrm{~nm}$ ), with decreasing intensity. At the same time, a new absorption appeared (AT at $592 \mathrm{~nm}$, EAAO at $590 \mathrm{~nm}$ ) which was designated to the exciton-type transition between the HOMO of the benzoid ring and the LUMO orbital of the quinoid ring [48,49]. As the intensity reached its maximum, the second absorption underwent a blue shift (AT from 592 to $590 \mathrm{~nm}$, EAAO from 590 to $580 \mathrm{~nm}$ ) [45].
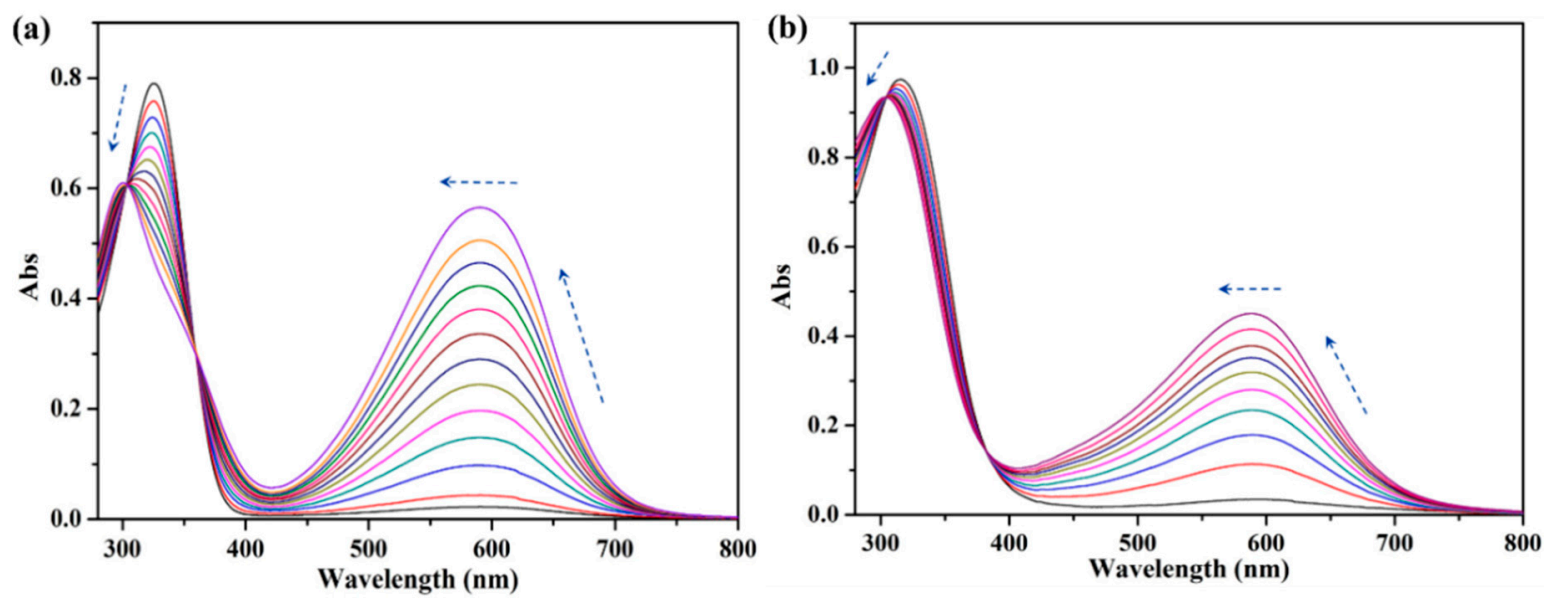

Figure 3. UV-Vis spectra monitoring chemical of (a) AT and (b) EAAO.

\subsection{Electroactivity of AT, EAAO and EIO Coatings}

The cyclic voltammetry of AT, EAAO, and EIO using $\mathrm{Ag} / \mathrm{AgCl}$ as the reference electrode was performed at a scan range of -0.2 to $1.0 \mathrm{~V}$ and a scan rate of $50 \mathrm{mV} \mathrm{s}^{-1}$ in $1.0 \mathrm{M} \mathrm{H}_{2} \mathrm{SO}_{4}$. As shown in Figure 4a, the cyclic voltammetry curve of the AT shows two pairs of redox peaks at $320 \mathrm{mV} / 200 \mathrm{mV}$ and $520 \mathrm{mV} / 420 \mathrm{mV}$, which correspond to the transitions from the leucoemeraldine base (LB) to the emeraldine base (EB) and the emeraldine base to the pernigraniline base (PNB), respectively (Scheme 2a) [50]. Moreover, the CV curve of the EAAO shows two pairs of redox peaks at $330 \mathrm{mV} / 200 \mathrm{mV}$ and $500 \mathrm{mV} / 350 \mathrm{mV}$, respectively, as shown in Figure $4 \mathrm{~b}$. In contrast, the CV results obtained from the EIO were different from those obtained from the EAAO. Only one pair of redox peaks at $360 \mathrm{mV} / 540 \mathrm{mV}$ could be observed, as shown in Figure 4c. The differences in the EAAO and the EIO systems could be attributed to their molecular structures (Scheme 2b,c). In the case of the EIO system, the secondary amines at the EAAO segment were condensed during the thermal imidization 
with carboxylic acid to form an imine, which would not allow for the formation of quinoid rings. Thus, the EIO existed only in one oxidation state [51], as shown in Scheme 2.

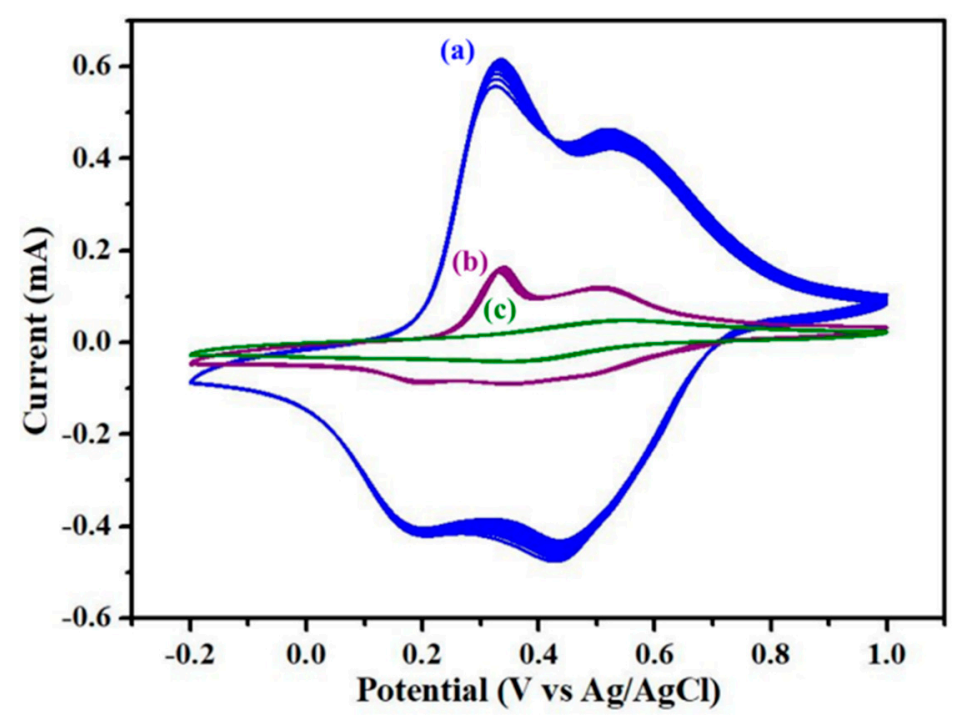

Figure 4. Cyclic voltammetry of (a) AT, (b) EAAO and (c) EIO were measured 10 cycles in aqueous $\mathrm{H}_{2} \mathrm{SO}_{4}(1.0 \mathrm{M})$ with scan rate of $50 \mathrm{mV} \mathrm{s}^{-1}$.

(b)

(a)
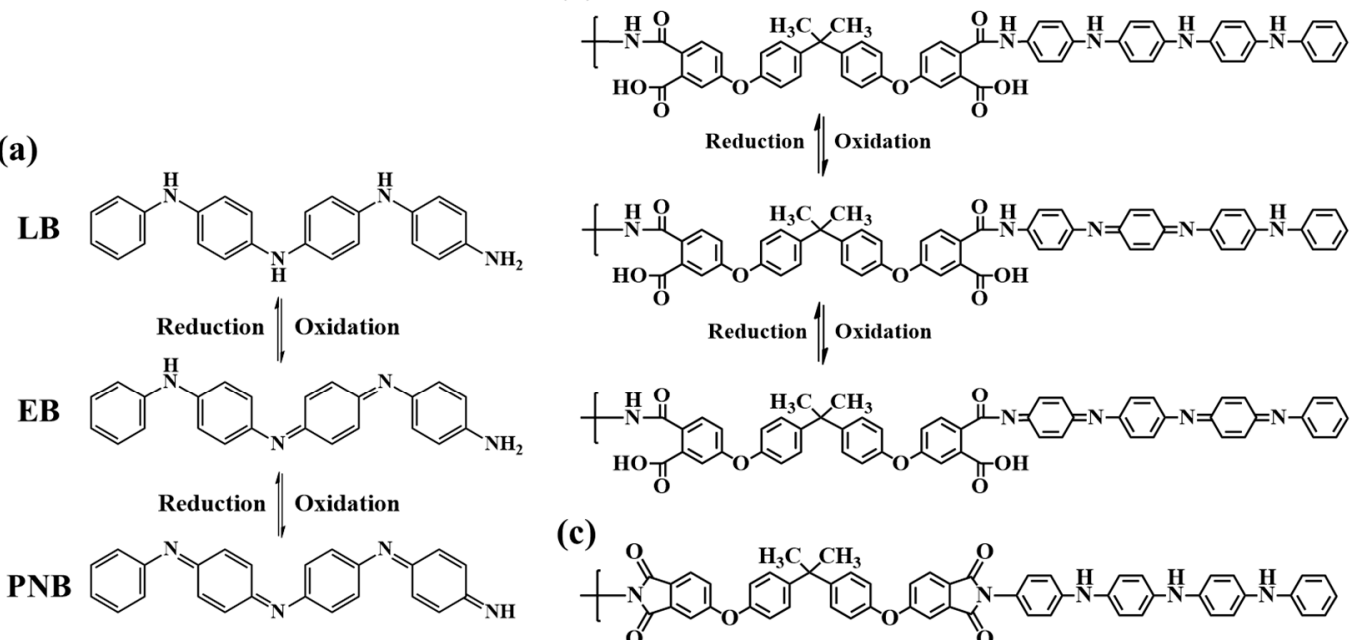

(c)



Scheme 2. Molecular structures of (a) AT, (b) EAAO and (c) EIO at various oxidation states.

\subsection{Potentiodynamic Measurements}

The polarization curves, electrochemical parameters of bare CRS, PI, AT, and EIO coatings, were exhibited in Figure 5. All the corrosion parameters including corrosion potential $\left(E_{c o r r}\right)$, corrosion current density $\left(I_{\text {corr }}\right)$, polarization resistance $\left(R_{p}\right)$, corrosion rate $(C R)$, anodic Tafel slope $\left(b_{a}\right)$ and cathodic Tafel slope $\left(b_{c}\right)$ are summarized in Table 2. Generally, a higher value of $E_{\text {corr }}$ and $R_{p}$, as well as lower values of $I_{\text {corr }}$ and $C R$, implied better corrosion protection $[34,44,52,53]$. Figure 5 a shows that bare CRS had the lowest $E_{\text {corr }}(-0.89 \mathrm{~V})$ and the highest $I_{\text {corr }}\left(2.52 \times 10^{-6} \mathrm{~A} \mathrm{~cm}^{-2}\right)$. By contrast, these values of the PI, AT and EIO coatings had their anti-corrosion performance improved. The values of 
$E_{\text {corr }}$ were increased to $-0.21 \mathrm{~V},-0.27 \mathrm{~V}$ and $-0.24 \mathrm{~V}$, respectively. Meanwhile, the values of $I_{\text {corr }}$ were decreased to $1.85 \times 10^{-10} \mathrm{~A} \mathrm{~cm}^{-2}, 4.30 \times 10^{-9} \mathrm{~A} \mathrm{~cm}^{-2}$, and $2.86 \times 10^{-9} \mathrm{~A} \mathrm{~cm}^{-2}$, respectively.
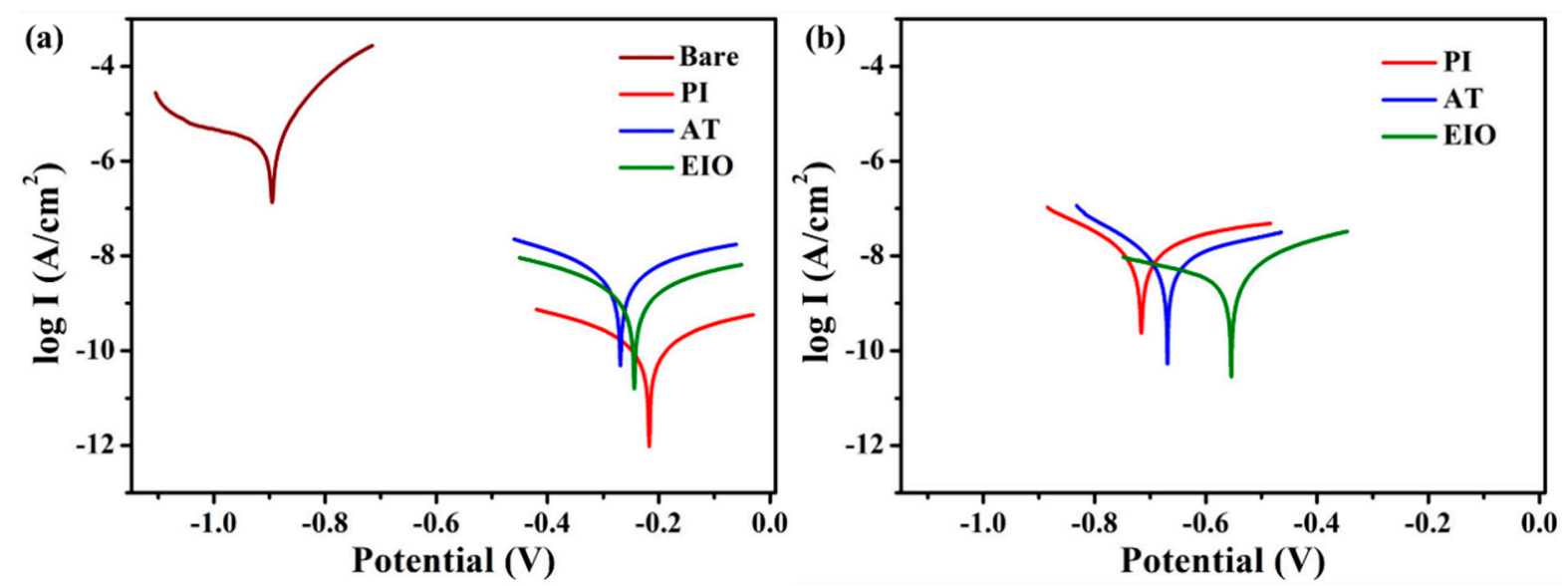

Figure 5. Tafel plots for the PI, AT and EIO coatings measured in $3.5 \mathrm{wt} . \% \mathrm{NaCl}$ solution for (a) 1 day and (b) 30 days.

Table 2. Electrochemical parameters derived from Tafel plots of the coatings in the saline solution after one-day immersion.

\begin{tabular}{cccccccc}
\hline \multirow{2}{*}{ Sample } & \multicolumn{7}{c}{ Electrochemical Measurements } \\
\cline { 2 - 8 } & $\mathbf{E}_{\text {corr }}(\mathbf{V})$ & $\mathbf{I}_{\text {corr }}\left(\mathbf{A ~ c m}^{-\mathbf{2}}\right)$ & $\mathbf{R}_{\mathbf{P}}\left(\boldsymbol{\Omega ~ c m}^{\mathbf{2}}\right)$ & $\boldsymbol{C R}(\mathbf{m m} /$ year $)$ & $\mathbf{b}_{\mathbf{a}}$ & $\mathbf{b}_{\mathbf{c}}$ & Thickness $(\boldsymbol{\mu m})$ \\
\hline Bare & -0.89 & $2.52 \times 10^{-6}$ & 8.69 & $2.90 \times 10^{-2}$ & 0.060 & 0.309 & - \\
PI & -0.21 & $1.85 \times 10^{-10}$ & $3.55 \times 10^{8}$ & $2.17 \times 10^{-6}$ & 0.305 & 0.300 & $22 \pm 1$ \\
AT & -0.27 & $4.30 \times 10^{-9}$ & $1.22 \times 10^{7}$ & $5.03 \times 10^{-5}$ & 0.260 & 0.226 & $21 \pm 1$ \\
EIO & -0.24 & $2.86 \times 10^{-9}$ & $2.88 \times 10^{7}$ & $3.35 \times 10^{-5}$ & 0.421 & 0.344 & $22 \pm 1$ \\
\hline
\end{tabular}

To further study the long-term anti-corrosion protection performance of the PI, AT and EIO coatings they were immersed in a $3.5 \mathrm{wt} . \% \mathrm{NaCl}$ solution for 30 days. The $E_{\text {corr }}$ and $I_{\text {corr }}$ of the PI coating were found to be $-0.71 \mathrm{~V}$ and $8.64 \times 10^{-9} \mathrm{~A} \mathrm{~cm}^{-2}$, respectively. Furthermore, both the AT and EIO coatings exhibited better anti-corrosion performance than the PI, as shown in Figure $5 \mathrm{~b}$. The $E_{\text {corr }}$ of the AT and EIO coatings were $-0.67 \mathrm{~V}$ and $-0.55 \mathrm{~V}$, respectively, while the $I_{\text {corr }}$ values were $7.85 \times 10^{-9} \mathrm{~A} \mathrm{~cm}^{-2}$ and $3.32 \times 10^{-9} \mathrm{~A} \mathrm{~cm}^{-2}$. The detailed values of corrosion parameters are summarized in Table 3. The results show that the EIO coating has the highest $E_{\text {corr }}$ and lowest $I_{\text {corr }}$, thus it can be concluded that it demonstrated the strongest anti-corrosion performance.

Table 3. Electrochemical parameters derived from Tafel plots of the coatings in the saline solution after 30 days immersion.

\begin{tabular}{cccccccc}
\hline \multirow{2}{*}{ Sample } & \multicolumn{7}{c}{ Electrochemical Measurements } \\
\cline { 2 - 8 } & $\mathbf{E}_{\text {corr }}(\mathbf{V})$ & $\mathbf{I}_{\text {corr }}\left(\mathbf{A ~ c m}^{-\mathbf{2}}\right)$ & $\mathbf{R}_{\mathbf{P}}\left(\boldsymbol{\Omega ~ c m}^{\mathbf{2}}\right)$ & $\boldsymbol{C R}(\mathbf{m m} /$ year) & $\mathbf{b}_{\mathbf{a}}$ & $\mathbf{b}_{\mathbf{c}}$ & Thickness $(\boldsymbol{\mu m})$ \\
\hline PI & -0.71 & $8.64 \times 10^{-9}$ & $3.66 \times 10^{6}$ & $1.01 \times 10^{-4}$ & 0.162 & 0.132 & $22 \pm 1$ \\
AT & -0.67 & $7.85 \times 10^{-9}$ & $5.33 \times 10^{6}$ & $9.19 \times 10^{-5}$ & 0.269 & 0.150 & $21 \pm 1$ \\
EIO & -0.55 & $3.32 \times 10^{-9}$ & $1.33 \times 10^{7}$ & $3.89 \times 10^{-5}$ & 0.138 & 0.385 & $22 \pm 1$ \\
\hline
\end{tabular}

\subsection{Electrochemical Impedance Spectroscopy (EIS) Measurements}

To further investigate the corrosion of the CRS electrode coated by PI, AT and EIO, the EIS measurements were conducted in $3.5 \mathrm{wt} . \% \mathrm{NaCl}$ solution. The EIS results are presented in Figure $6 \mathrm{a}$. The equivalent electric circuits were shown in Figure 7. $R_{s}$ is the solution resistance between the working electrode and the reference electrode, $R_{p o}$ and $C_{c}$ correspond to the coating pore resistance and 
coating capacitance, $R_{c t}$ and $C_{d l}$ represent the charge transfer resistance and double-layer capacitance, and $Z_{w}$ is the Warburg resistance [46]. The Nyquist and Bode plots of the neat CRS are shown as comparison studies. As shown in Figure 6a, at the initial immersion stage, all of the samples were semi-circular, indicating the CRS had increased anti-corrosion attributes [54-57]. The EIS data were fitted with the equivalent circuit in Figure $7 \mathrm{a}$.
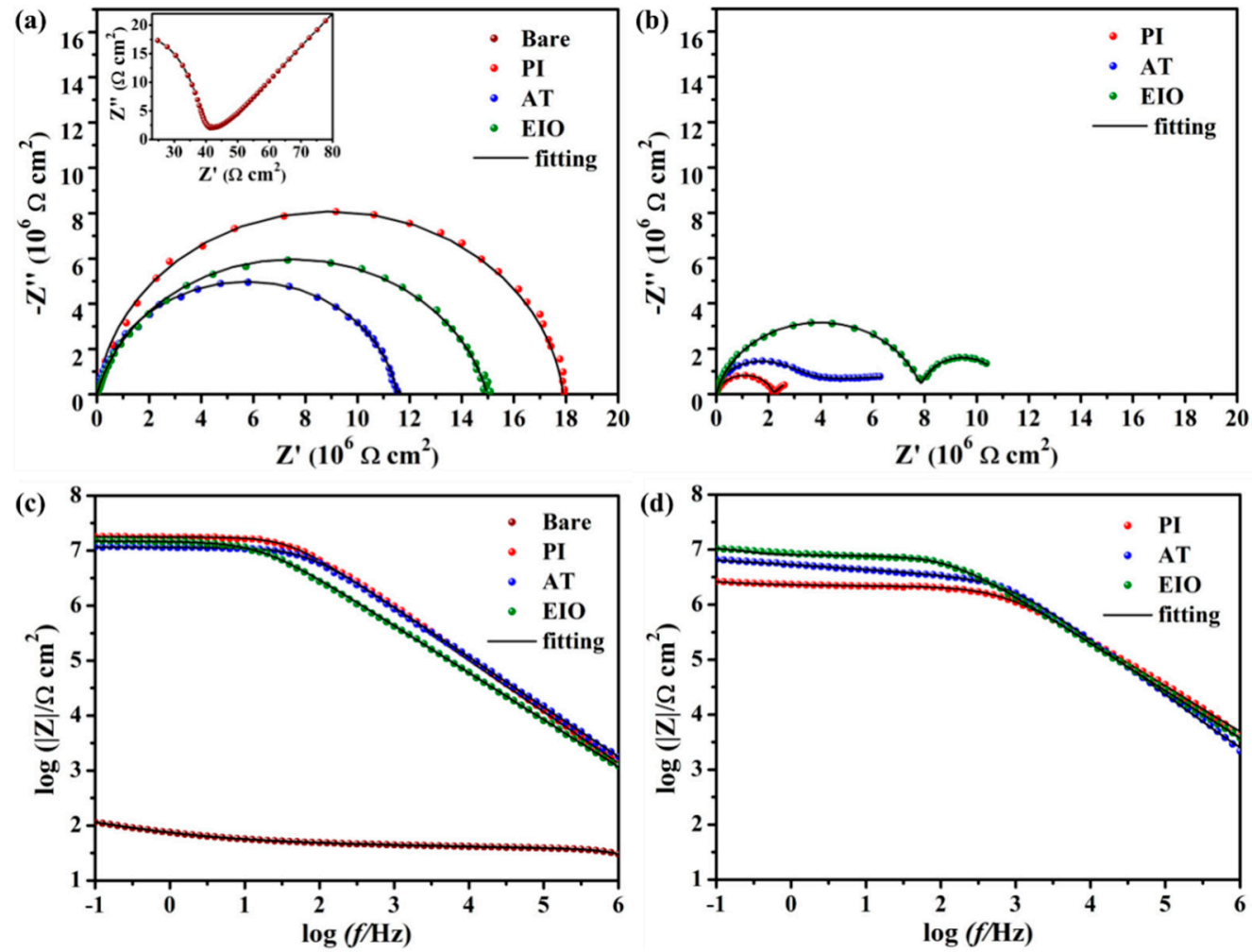

Figure 6. The PI, AT, and EIO coatings measured in $3.5 \mathrm{wt} . \% \mathrm{NaCl}$ solution for Nyquist plots for (a) 1 day, (b) 30 days and Bode plots (c) 1 day and (d) 30 days. The inset shows the Nyquist plots for neat CRS.
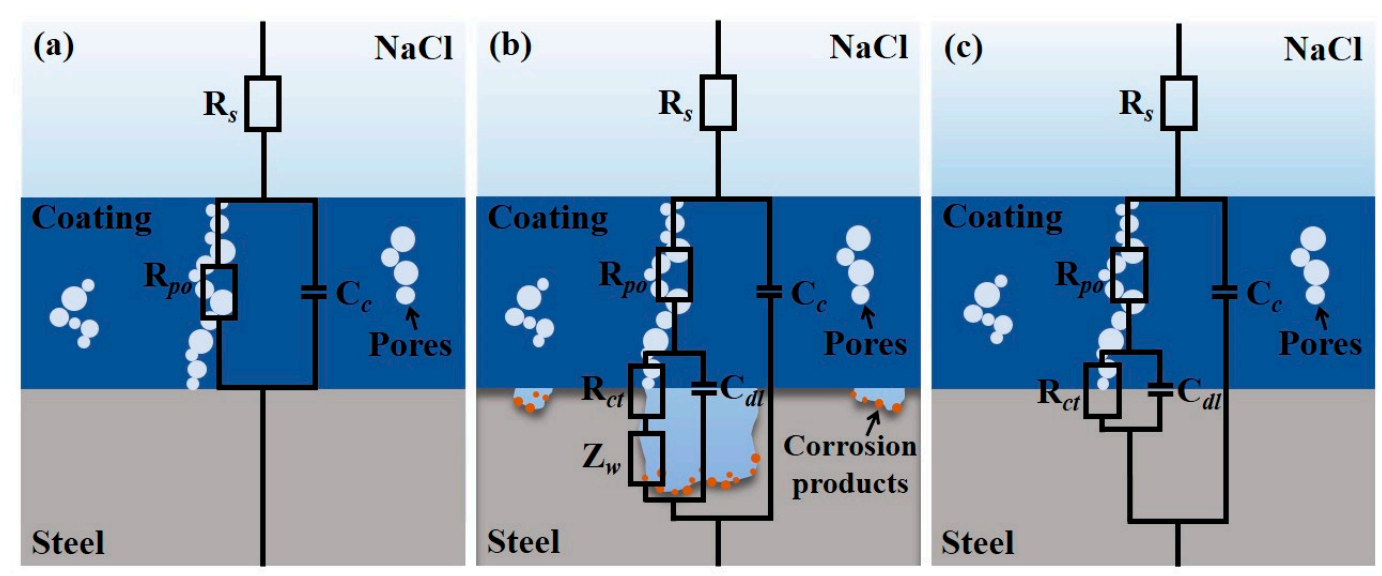

Figure 7. The equivalent electric circuits of (a) all of coatings immersion 1 day; (b) PI, (c) AT and EIO immersion 30 days.

After long-term immersion, the Nyquist plots of the PI exhibited shrinking capacitive arcs followed by a tiny diffusion tail, indicating that the metal surface corrosion was caused primarily by a charge reaction [58-60]. Moreover, the electrochemical impedance spectra of AT and EIO show two time constants and two capacitive arcs, as shown in Figure $6 \mathrm{~b}$. The high-frequency capacitive arc reflected 
the properties of the coating, while the low-frequency capacitive loop reflected the corrosion of the metal beneath the coating [61]. The larger radius of the semicircle signified that the coating has a high impedance during the water seepage stage due to the passive metal oxide layers formed by the segments of aniline tetramer, hindering the penetration of water and oxygen and preventing further corrosion of the CRS substrate. The measured results of the EIS were fitted with the equivalent circuit in Figure $7 b, c$.

The Bode plots of the PI, AT, and EIO were shown in Figure $6 c, d$. In general, the lowest frequency region of the impedance modulus could be used to roughly estimate the coating resistance [62,63]. At the initial immersion stage, the $|Z|_{0.1 \mathrm{~Hz}}$ value for bare, PI, AT and EIO were $1.14 \times 10^{2}, 1.79 \times 10^{7}$, $1.15 \times 10^{7}$ and $1.49 \times 10^{7} \mathrm{ohm} \cdot \mathrm{cm}^{2}$, respectively. After 30 days of immersion, the $|\mathrm{Z}|_{0.1 \mathrm{~Hz}}$ value of the PI, AT and EIO were dropped to $2.60 \times 10^{6}, 6.38 \times 10^{6}$ and $1.05 \times 10^{7} \mathrm{ohm} \cdot \mathrm{cm}^{2}$, respectively. Both the AT and EIO coatings show better anti-corrosion effect than the PI during the long-term immersion period. The reason was attributed to the existing aniline tetramer units in the coatings, which can passivate the metal surface to form a protective iron oxide film. The results of the EIS were consistent with previous Tafel plot studies.

Figure 8 shows the initial $R_{p o}$ of all the coatings before and after the 30 days immersion period, after which the $R_{p o}$ of all the samples had decreased due to defects in the coatings. The AT $\left(3.66 \times 10^{6} \mathrm{ohm} \cdot \mathrm{cm}^{2}\right)$ and EIO $\left(7.93 \times 10^{6} \mathrm{ohm} \cdot \mathrm{cm}^{2}\right)$ coatings show higher pore resistance than the PI $\left(2.18 \times 10^{6} \mathrm{ohm} \cdot \mathrm{cm}^{2}\right)$ due to the formation of passive metal oxide layers. Furthermore, the $R_{p o}$ of the EIO was the highest among all the coatings, indicating that it offered the best protection for the CRS. This may be the result of the EIO coating not only forming passive metal oxide layers but also providing the charge transfer complex (CTC), a property that has been the subject of many studies [64]. CTC was formed between dianhydride and diamine groups in polyimide systems and is largely responsible for some of the valuable properties of polyimides. The increased interchain attractive forces resulting from such interactions are proposed to increase the rigidity of the chain, which increases the density of the EIO coating and grants it stronger anti-corrosion properties.

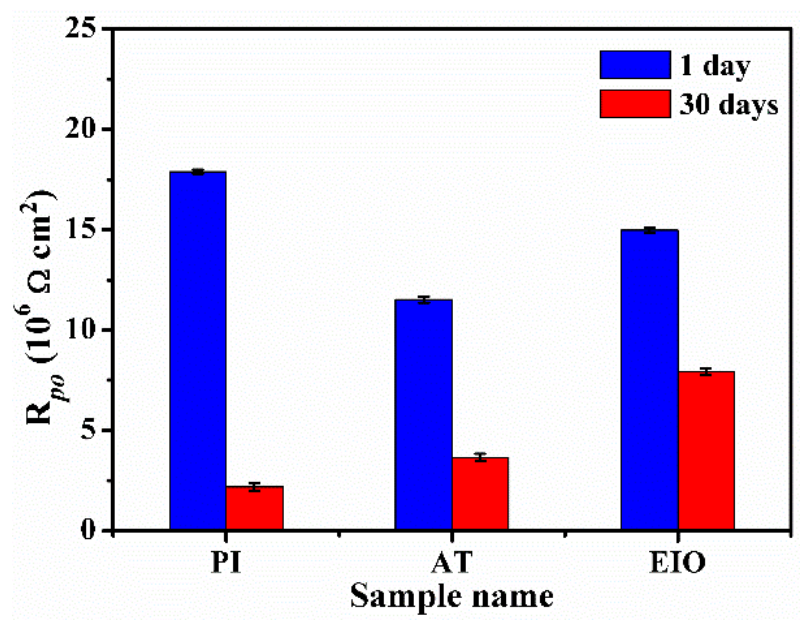

Figure 8. Coating pores resistance values of the PI, AT, and EIO coatings immersed in $3.5 \mathrm{wt} . \% \mathrm{NaCl}$ solution for 1 day and 30 days.

\subsection{Corrosion Products and Corrosion Mechanism Analysis}

In further studies the SEM and XPS were used to confirm the formation of passive metal oxide layers $\left(\mathrm{Fe}_{2} \mathrm{O}_{3}\right)$ upon the surface of the CRS. For comparison, the SEM image of a ground CRS surface is shown in Figure 9a. Figure $9 b$ shows the ground CRS surface after the 30 days immersion period in a 3.5 wt.\% NaCl solution, where dense, irregular projections and particles can be observed. Moreover, Figure $9 \mathrm{c}-\mathrm{d}$ show the surface of the CRS where PI, AT, and EIO coatings were removed after a saline immersion treatment. It is observed from Figure $9 \mathrm{c}$ that sparse granular substances covered the surface 
of the CRS. This suggests that the coating is unable to completely suppress the penetration of the aggressive corrosive medium (chlorine and dissolved oxygen ions) into the underlying substrate during long-term immersion treatment. On the other hand, the AT and EIO coatings were relatively cleaner, as shown in Figure 9d,e. This indicates that a passive metal oxide layers formed on the CRS surface.
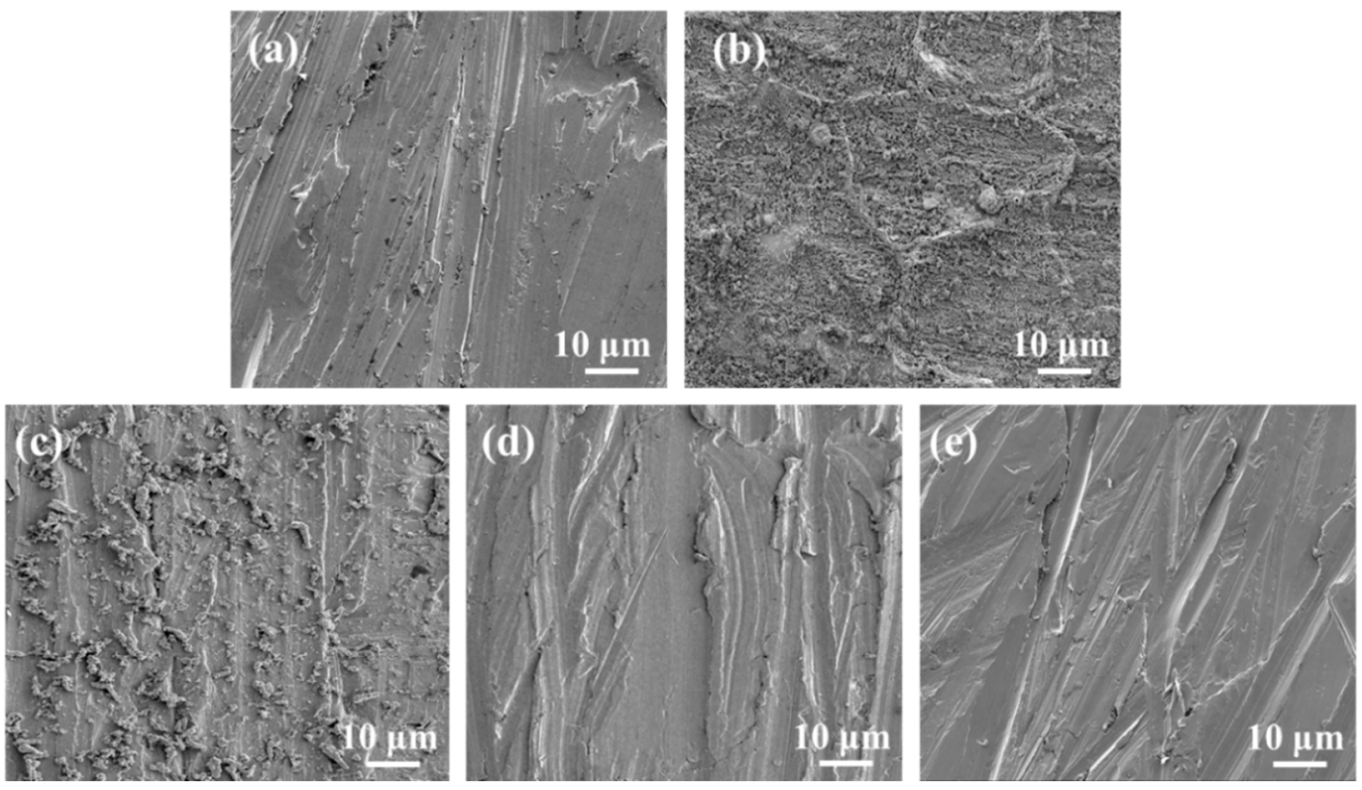

Figure 9. SEM images for (a) ground CRS, and the surface of CRS coated with the (b) bare, (c) PI, (d) AT and (e) EIO immersed in $3.5 \mathrm{wt} . \% \mathrm{NaCl}$ solution duration for 30 days.

The chemical composition of the passivating oxide layers was determined by XPS. The binding energy vs. intensity plots for iron oxide layers are shown in Figure 10. For comparison, the XPS plots of the ground CRS surface and CRS surface beneath PI are shown in Figure 10a,b. As shown in Figure 10c,d, the CRS surface coated with the AT and EIO all exhibited two binding energy peaks of Fe $2 \mathrm{p}_{3 / 2}$ and $\mathrm{Fe} 2 \mathrm{p}_{1 / 2}$ of $\mathrm{Fe}_{2} \mathrm{O}_{3}$ at $710.7 \mathrm{eV}$ and $724.1 \mathrm{eV}$, respectively. Furthermore, a distinctive shake-up satellite at around $719.1 \mathrm{eV}$ indicates that the passivation oxide layer consists mainly of $\mathrm{Fe}_{2} \mathrm{O}_{3}[65,66]$. The corrosion process in neutral solutions is presented in the following equations $[67,68]$ and schematic diagrams (Figure 11):

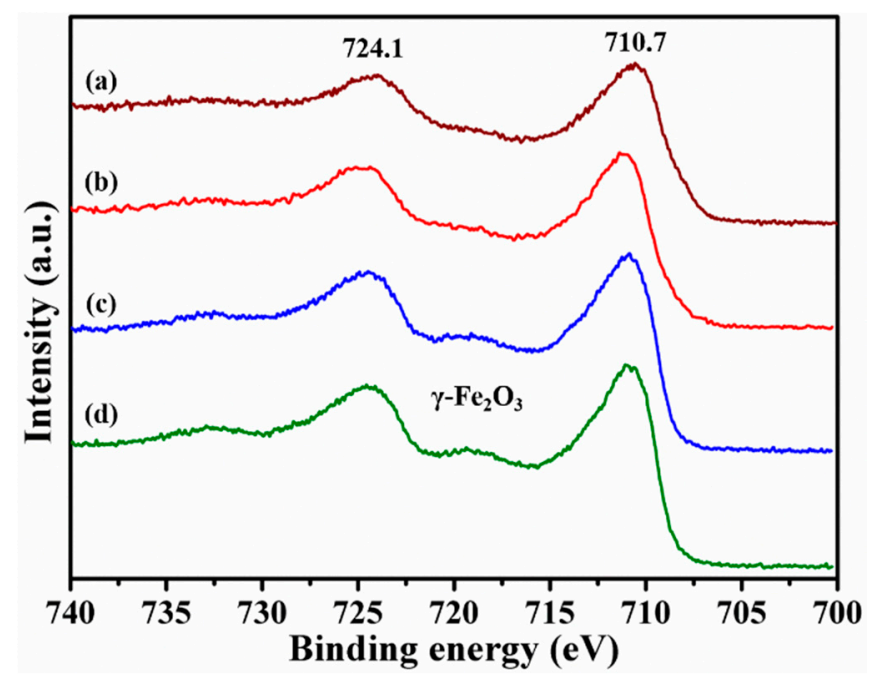

Figure 10. XPS Fe 2p core level spectra of (a) ground CRS, (b) PI, (c) AT, and (d) EIO. 


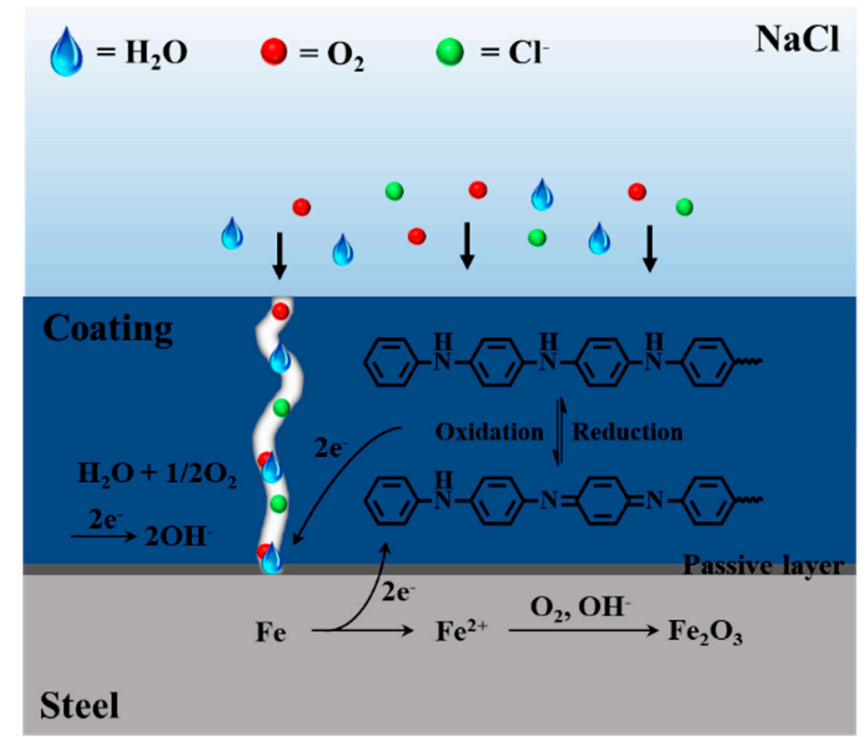

Figure 11. Schematic diagrams of the mechanism of CRS passivation by EIO coatings.

anodic reaction:

$$
\mathrm{Fe} \rightarrow \mathrm{Fe}^{2+}+2 \mathrm{e}^{-}
$$

$\mathrm{O}_{2}$ reduction takes place at the cathode:

$$
1 / 2 \mathrm{O}_{2}+2 \mathrm{e}^{-}+\mathrm{H}_{2} \mathrm{O} \rightarrow 2 \mathrm{OH}^{-}
$$

chemical process:

$$
2 \mathrm{OH}^{-}+\mathrm{Fe}^{2+} \rightarrow \mathrm{Fe}(\mathrm{OH})_{2} \rightarrow \mathrm{Fe}(\mathrm{OH})_{3} \rightarrow \mathrm{Fe}_{2} \mathrm{O}_{3}
$$

\section{Conclusions}

In this study, the aniline tetramer capped electroactive imide oligomer (EIO) was successfully synthesized and applied as an anti-corrosion coating for a cold-rolled steel electrode. The precursor of the EIO, electroactive amic acid oligomer (EAAO), is limited due to its high solubility in common organic solvents. The anti-corrosive properties of the EIO coating were evaluated by Tafel curves and EIS. Further investigation of the oxidation products underneath the coating using SEM and XPS concluded that the EIO coating facilitated the formation of passive metal oxide layers. This study offers a novel method to prepare the soluble electroactive oligomer, which might be useful when applied to protecting metals from corrosion.

Author Contributions: Conceptualization Y.-C.C.; methodology, software, formal analysis, and investigation B.-S.H. and G.-H.L.; experiment, data curation and writing-original draft preparation B.-S.H.; writing-review and editing M.-H.T., T.-I.Y., and Y.-C.C.; project administration and funding acquisition M.-H.T. All authors have read and agreed to the published version of the manuscript.

Funding: This material is based on work supported by the Ministry of Science and Technology, Taiwan, ROC (grant No. MOST 108-2221-E-167 -020 -; MOST 108-2917-I-167 -001 -).

Conflicts of Interest: The authors declare no conflict of interest.

\section{References}

1. George, F.; Hays, P. Now is the Time; World Corrosion Organization: New York, NY, USA, 2016.

2. Li, P.; He, X.; Huang, T.-C.; White, K.L.; Zhang, X.; Liang, H.; Nishimura, R.; Sue, H.-J. Highly effective anti-corrosion epoxy spray coatings containing self-assembled clay in smectic order. J. Mater. Chem. A 2015, 3, 2669-2676. [CrossRef] 
3. Li, P.; Huang, T.-C.; White, K.L.; Hawkins, S.; Kotaki, M.; Nishimura, R.; Sue, H.-J. Spray-coated epoxy barrier films containing high aspect ratio functionalized graphene nanosheets. RSC Adv. 2015, 5, 102633-102642. [CrossRef]

4. Huang, T.-C.; Lai, G.-H.; Li, C.-E.; Tsai, M.-H.; Wan, P.-Y.; Chung, Y.-H.; Lin, M.-H. Advanced anti-corrosion coatings prepared from [small alpha]-zirconium phosphate/polyurethane nanocomposites. RSC Adv. 2017, 7, 9908-9913. [CrossRef]

5. Lai, G.H.; Huang, T.C.; Tseng, I.H.; Huang, B.S.; Yang, T.I.; Tsai, M.H. Transparency anticorrosion coatings prepared from alumina-covered graphene oxide/polyimide nanocomposites. Express Polym. Lett. 2019, 13, 772-784. [CrossRef]

6. Liang, J.; Srinivasan, P.B.; Blawert, C.; Dietzel, W. Comparison of electrochemical corrosion behaviour of mgo and $\mathrm{zro}_{2}$ coatings on am50 magnesium alloy formed by plasma electrolytic oxidation. Corros. Sci. 2009, 51, 2483-2492. [CrossRef]

7. Palanivel, V.; Zhu, D.; van Ooij, W.J. Nanoparticle-filled silane films as chromate replacements for aluminum alloys. Prog. Org. Coat. 2003, 47, 384-392. [CrossRef]

8. Xiang, N.; Song, R.-G.; Zhuang, J.-J.; Song, R.-X.; Lu, X.-Y.; Su, X.-P. Effects of current density on microstructure and properties of plasma electrolytic oxidation ceramic coatings formed on 6063 aluminum alloy. Trans. Nonferrous Met. Soc. China 2016, 26, 806-813. [CrossRef]

9. Anitha, R.; Chitra, S.; Hemapriya, V.; Chung, I.-M.; Kim, S.-H.; Prabakaran, M. Implications of eco-addition inhibitor to mitigate corrosion in reinforced steel embedded in concrete. Constr. Build. Mater. 2019, 213, 246-256. [CrossRef]

10. Ituen, E.B.; Akaranta, O.; Umoren, S.A. N-acetyl cysteine based corrosion inhibitor formulations for steel protection in 15\% hcl solution. J. Mol. Liq. 2017, 246, 112-118. [CrossRef]

11. Peng, S.; Zhao, W.; Li, H.; Zeng, Z.; Xue, Q.; Wu, X. The enhancement of benzotriazole on epoxy functionalized silica sol-gel coating for copper protection. Appl. Surf. Sci. 2013, 276, 284-290. [CrossRef]

12. Eduok, U.; Suleiman, R.; Gittens, J.; Khaled, M.; Smith, T.J.; Akid, R.; El Ali, B.; Khalil, A. Anticorrosion/antifouling properties of bacterial spore-loaded sol-gel type coating for mild steel in saline marine condition: A case of thermophilic strain of bacillus licheniformis. RSC Adv. 2015, 5, 93818-93830. [CrossRef]

13. Rohwerder, M.; Michalik, A. Conducting polymers for corrosion protection: What makes the difference between failure and success? Electrochim. Acta 2007, 53, 1300-1313. [CrossRef]

14. Yu, Y.-H.; Jen, C.-C.; Huang, H.-Y.; Wu, P.-C.; Huang, C.-C.; Yeh, J.-M. Preparation and properties of heterocyclically conjugated poly(3-hexylthiophene)-clay nanocomposite materials. J. Appl. Polym. Sci. 2004, 91, 3438-3446. [CrossRef]

15. Hosseini, M.; Fotouhi, L.; Ehsani, A.; Naseri, M. Enhancement of corrosion resistance of polypyrrole using metal oxide nanoparticles: Potentiodynamic and electrochemical impedance spectroscopy study. J. Colloid Interface Sci. 2017, 505, 213-219. [CrossRef]

16. Song, E.; Choi, J.-W. Conducting polyaniline nanowire and its applications in chemiresistive sensing. Nanomaterials 2013, 3, 498-523. [CrossRef]

17. Ćirić-Marjanović, G. Recent advances in polyaniline composites with metals, metalloids and nonmetals. Synth. Met. 2013, 170, 31-56. [CrossRef]

18. Chang, C.-H.; Huang, T.-C.; Peng, C.-W.; Yeh, T.-C.; Lu, H.-I.; Hung, W.-I.; Weng, C.-J.; Yang, T.-I.; Yeh, J.-M. Novel anticorrosion coatings prepared from polyaniline/graphene composites. Carbon 2012, 50, 5044-5051. [CrossRef]

19. Qiu, S.; Chen, C.; Cui, M.; Li, W.; Zhao, H.; Wang, L. Corrosion protection performance of waterborne epoxy coatings containing self-doped polyaniline nanofiber. Appl. Surf. Sci. 2017, 407, 213-222. [CrossRef]

20. Sarkar, N.; Sahoo, G.; Das, R.; Prusty, G.; Sahu, D.; Swain, S.K. Anticorrosion performance of three-dimensional hierarchical pani@bn nanohybrids. Ind. Eng. Chem. Res. 2016, 55, 2921-2931. [CrossRef]

21. Grgur, B.N. On the role of aniline oligomers on the corrosion protection of mild steel. Synth. Met. 2014, 187, 57-60. [CrossRef]

22. Gu, L.; Liu, S.; Zhao, H.; Yu, H. Anticorrosive oligoaniline-containing electroactive siliceous hybrid materials. RSC Adv. 2015, 5, 56011-56019. [CrossRef] 
23. Huang, H.-Y.; Lee, Y.-T.; Yeh, L.-C.; Jian, J.-W.; Huang, T.-C.; Liang, H.-T.; Yeh, J.-M.; Chou, Y.-C. Photoactively electroactive polyamide with azo group in the main chain via oxidative coupling polymerization. Polym. Chem. 2013, 4, 343-350. [CrossRef]

24. Yeh, L.-C.; Huang, T.-C.; Huang, Y.-P.; Huang, H.-Y.; Chen, H.-H.; Yang, T.-I.; Yeh, J.-M. Synthesis electroactive polyurea with aniline-pentamer-based in the main chain and its application in electrochemical sensor. Electrochim. Acta 2013, 94, 300-306. [CrossRef]

25. Wang, Y.; Liu, J.; Tran, H.D.; Mecklenburg, M.; Guan, X.N.; Stieg, A.Z.; Regan, B.C.; Martin, D.C.; Kaner, R.B. Morphological and dimensional control via hierarchical assembly of doped oligoaniline single crystals. J. Am. Chem. Soc. 2012, 134, 9251-9262. [CrossRef] [PubMed]

26. Shao, Z.; Yu, Z.; Hu, J.; Chandrasekaran, S.; Lindsay, D.M.; Wei, Z.; Faul, C.F.J. Block-like electroactive oligo(aniline)s: Anisotropic structures with anisotropic function. J. Mater. Chem. 2012, 22, 16230-16234. [CrossRef]

27. Sun, N.; Meng, S.; Chao, D.; Zhou, Z.; Du, Y.; Wang, D.; Zhao, X.; Zhou, H.; Chen, C. Highly stable electrochromic and electrofluorescent dual-switching polyamide containing bis(diphenylamino)-fluorene moieties. Polym. Chem. 2016, 7, 6055-6063. [CrossRef]

28. Yan, Y.; Sun, N.; Li, F.; Jia, X.; Wang, C.; Chao, D. Multiple stimuli-responsive fluorescence behavior of novel polyamic acid bearing oligoaniline, triphenylamine, and fluorene groups. ACS Appl. Mater. Interfaces 2017, 9, 6497-6503. [CrossRef]

29. Yan, Y.; Jia, X.; Feng, M.; Wang, C.; Chao, D. Synthesis and electrochemical characterization of polyamic acid containing oligoaniline and triphenylamine. J. Polym. Sci. Part A Polym. Chem. 2017, 55, 1669-1673. [CrossRef]

30. Huang, H.-Y.; Huang, T.-C.; Lin, J.-C.; Chang, J.-H.; Lee, Y.-T.; Yeh, J.-M. Advanced environmentally friendly coatings prepared from amine-capped aniline trimer-based waterborne electroactive polyurethane. Mater. Chem. Phys. 2013, 137, 772-780. [CrossRef]

31. Liu, T.; Li, J.; Li, X.; Qiu, S.; Ye, Y.; Yang, F.; Zhao, H. Effect of self-assembled tetraaniline nanofiber on the anticorrosion performance of waterborne epoxy coating. Prog. Org. Coat. 2019, 128, 137-147. [CrossRef]

32. Huang, C.-C.; Jang, G.-W.; Chang, K.-C.; Hung, W.-I.; Yeh, J.-M. High-performance polyimide-clay nanocomposite materials based on a dual intercalating agent system. Polym. Int. 2008, 57, 605-611. [CrossRef]

33. Huang, T.-C.; Lin, S.-T.; Yeh, L.-C.; Chen, C.-A.; Huang, H.-Y.; Nian, Z.-Y.; Chen, H.-H.; Yeh, J.-M. Aniline pentamer-based electroactive polyimide prepared from oxidation coupling polymerization for electrochemical sensing application. Polymer 2012, 53, 4373-4379. [CrossRef]

34. Huang, T.-C.; Yeh, L.-C.; Huang, H.-Y.; Nian, Z.-Y.; Yeh, Y.-C.; Chou, Y.-C.; Yeh, J.-M.; Tsai, M.-H. The use of a carbon paste electrode mixed with multiwalled carbon nanotube/electroactive polyimide composites as an electrode for sensing ascorbic acid. Polym. Chem. 2014, 5, 630-637. [CrossRef]

35. Huang, T.-C.; Hsieh, C.-F.; Yeh, T.-C.; Lai, C.-L.; Tsai, M.-H.; Yeh, J.-M. Comparative studies on corrosion protection properties of polyimide-silica and polyimide-clay composite materials. J. Appl. Polym. Sci. 2011, 119, 548-557. [CrossRef]

36. Huang, H.-Y.; Huang, T.-C.; Yeh, T.-C.; Tsai, C.-Y.; Lai, C.-L.; Tsai, M.-H.; Yeh, J.-M.; Chou, Y.-C. Advanced anticorrosive materials prepared from amine-capped aniline trimer-based electroactive polyimide-clay nanocomposite materials with synergistic effects of redox catalytic capability and gas barrier properties. Polymer 2011, 52, 2391-2400. [CrossRef]

37. Lyu, W.; Feng, J.; Yan, W.; Faul, C.F.J. Self-assembly of tetra(aniline) nanowires in acidic aqueous media with ultrasonic irradiation. J. Mater. Chem. C 2015, 3, 11945-11952. [CrossRef]

38. Stern, M.; Geary, A.L. Electrochemical polarization: I. A theoretical analysis of the shape of polarization curves. J. Electrochem. Soc. 1957, 104, 56-63. [CrossRef]

39. Duran, B.; Turhan, M.C.; Bereket, G.; Saraç, A.S. Electropolymerization, characterization and corrosion performance of poly(n-ethylaniline) on copper. Electrochim. Acta 2009, 55, 104-112. [CrossRef]

40. Huang, T.-C.; Yeh, T.-C.; Huang, H.-Y.; Ji, W.-F.; Lin, T.-C.; Chen, C.-A.; Yang, T.-I.; Yeh, J.-M. Electrochemical investigations of the anticorrosive and electrochromic properties of electroactive polyamide. Electrochim. Acta 2012, 63, 185-191. [CrossRef] 
41. Sheng, X.; Cai, W.; Zhong, L.; Xie, D.; Zhang, X. Synthesis of functionalized graphene/polyaniline nanocomposites with effective synergistic reinforcement on anticorrosion. Ind. Eng. Chem. Res. 2016, 55, 8576-8585. [CrossRef]

42. Yeh, L.-C.; Huang, T.-C.; Lin, Y.-J.; Lai, G.-H.; Yang, T.-I.; Lo, A.-Y.; Yeh, J.-M. Electroactive polyamide modified carbon paste electrode for the determination of ascorbic acid. Int. J. Green Energy 2016, 13, 1334-1341. [CrossRef]

43. Huang, T.C.; Yeh, L.C.; Lai, G.H.; Lai, F.Y.; Yang, T.I.; Huang, Y.J.; Lo, A.Y.; Yeh, J.M. Electroactive polyurea/cnt composite-based electrode for detection of vitamin c. Express Polym. Lett. 2016, 10, 450-461. [CrossRef]

44. Huang, T.-C.; Yeh, L.-C.; Lai, G.-H.; Huang, B.-S.; Yang, T.-I.; Hsu, S.-C.; Lo, A.-Y.; Yeh, J.-M. Advanced superhydrophobic electroactive fluorinated polyimide and its application in anticorrosion coating. Int. J. Green Energy 2017, 14, 113-120. [CrossRef]

45. Huang, T.-C.; Yeh, T.-C.; Huang, H.-Y.; Ji, W.-F.; Chou, Y.-C.; Hung, W.-I.; Yeh, J.-M.; Tsai, M.-H. Electrochemical studies on aniline-pentamer-based electroactive polyimide coating: Corrosion protection and electrochromic properties. Electrochim. Acta 2011, 56, 10151-10158. [CrossRef]

46. Sun, W.; Wang, L.; Wu, T.; Wang, M.; Yang, Z.; Pan, Y.; Liu, G. Inhibiting the corrosion-promotion activity of graphene. Chem. Mater. 2015, 27, 2367-2373. [CrossRef]

47. Wei, H.; Wu, X.; Hu, B.; Fang, X. Preparation, characterization, and properties of poly(thioether ether ketone imide)s from isomeric bis(chlorophthalimide)s. Polym. Adv. Technol. 2011, 22, 2488-2495. [CrossRef]

48. Yang, R.; Chao, D.; Liu, H.; Berda, E.B.; Wang, S.; Jia, X.; Wang, C. Synthesis, electrochemical properties and inhibition performance of water-soluble self-doped oligoaniline derivative. Electrochim. Acta 2013, 93, 107-113. [CrossRef]

49. Chao, D.; Jia, X.; Liu, H.; He, L.; Cui, L.; Wang, C.; Berda, E.B. Novel electroactive poly(arylene ether sulfone) copolymers containing pendant oligoaniline groups: Synthesis and properties. J. Od Polymrt Sci. Part A Polym. Chem. 2011, 49, 1605-1614. [CrossRef]

50. Jia, X.; Chao, D.; Liu, H.; He, L.; Zheng, T.; Bian, X.; Wang, C. Synthesis and properties of novel electroactive poly(amic acid) and polyimide copolymers bearing pendant oligoaniline groups. Polym. Chem. 2011, 2, 1300-1306. [CrossRef]

51. Lv, W.; Feng, J.; Yan, W. Electrochemical potential-responsive tetra(aniline) nanocapsules via self-assembly. RSC Adv. 2015, 5, 27862-27866. [CrossRef]

52. Liu, M.; Zhang, X.; Wang, D.; Cheng, J.; Pang, X.; Qu, W.; Li, C.; Li, S. Facile fabrication of superhydrophobic surface from fluorinated poss acrylate copolymer via one-step breath figure method and its anti-corrosion property. Polymers 2019, 11, 1953. [CrossRef] [PubMed]

53. Chen, K.-S.; Chang, S.-J.; Feng, C.-K.; Lin, W.-L.; Liao, S.-C. Plasma deposition and uv light induced surface grafting polymerization of nipaam on stainless steel for enhancing corrosion resistance and its drug delivery property. Polymers 2018, 10, 1009. [CrossRef] [PubMed]

54. Medrano-Vaca, M.G.; Gonzalez-Rodriguez, J.G.; Nicho, M.E.; Casales, M.; Salinas-Bravo, V.M. Corrosion protection of carbon steel by thin films of poly(3-alkyl thiophenes) in $0.5 \mathrm{~m} \mathrm{~h}_{2} \mathrm{so}_{4}$. Electrochim. Acta 2008, 53, 3500-3507. [CrossRef]

55. Lin, C.H.; Duh, J.G. Electrochemical impedance spectroscopy (eis) study on corrosion performance of cralsin coated steels in 3.5wt.\% nacl solution. Surf. Coat. Technol. 2009, 204, 784-787. [CrossRef]

56. Deng, W.; Lin, P.; Li, Q.; Mo, G. Ultrafine-grained copper produced by machining and its unusual electrochemical corrosion resistance in acidic chloride pickling solutions. Corros. Sci. 2013, 74, 44-49. [CrossRef]

57. Gao, X.; Zhao, C.; Lu, H.; Gao, F.; Ma, H. Influence of phytic acid on the corrosion behavior of iron under acidic and neutral conditions. Electrochim. Acta 2014, 150, 188-196. [CrossRef]

58. Iroh, J.O.; Su, W. Corrosion performance of polypyrrole coating applied to low carbon steel by an electrochemical process. Electrochim. Acta 2000, 46, 15-24. [CrossRef]

59. Sathiyanarayanan, S.; Muthukrishnan, S.; Venkatachari, G.; Trivedi, D.C. Corrosion protection of steel by polyaniline (pani) pigmented paint coating. Prog. Org. Coat. 2005, 53, 297-301. [CrossRef]

60. Mrad, M.; Dhouibi, L.; Triki, E. Dependence of the corrosion performance of polyaniline films applied on stainless steel on the nature of electropolymerisation solution. Synth. Met. 2009, 159, 1903-1909. [CrossRef]

61. Du, P.; Qiu, S.; Liu, C.; Liu, G.; Zhao, H.; Wang, L. In situ polymerization of sulfonated polyaniline in layered double hydroxide host matrix for corrosion protection. New J. Chem. 2018, 42, 4201-4209. [CrossRef] 
62. De Rosa, R.L.; Earl, D.A.; Bierwagen, G.P. Statistical evaluation of eis and enm data collected for monitoring corrosion barrier properties of organic coatings on al-2024-t3. Corros. Sci. 2002, 44, 1607-1620. [CrossRef]

63. Luo, B.; Xu, A.; Liang, Y.; Huang, Z.; Qiao, Z.; Xia, D.-H. Evaluation on protective performance of organic coatings by analyzing the change rate of phase angle at high frequency. Int. J. Electrochem. Sci. 2012, 7, 8859-8868.

64. Yan, J.; Zhang, B.; Wang, Z. Monodispersed ultramicroporous semi-cycloaliphatic polyimides for the highly efficient adsorption of $\mathrm{CO}_{2}, \mathrm{~h}_{2}$ and organic vapors. Polym. Chem. 2016, 7, 7295-7303. [CrossRef]

65. Yamashita, T.; Hayes, P. Analysis of xps spectra of $\mathrm{fe}^{2+}$ and $\mathrm{fe}^{3+}$ ions in oxide materials. Appl. Surf. Sci. 2008, 254, 2441-2449. [CrossRef]

66. Fujii, T.; de Groot, F.M.F.; Sawatzky, G.A.; Voogt, F.C.; Hibma, T.; Okada, K. In situ xps analysis of various iron oxide films grown by no ${ }_{2}$-assisted molecular-beam epitaxy. Phys. Rev. B 1999, 59, 3195-3202. [CrossRef]

67. Sathiyanarayanan, S.; Muthkrishnan, S.; Venkatachari, G. Corrosion protection of steel by polyaniline blended coating. Electrochim. Acta 2006, 51, 6313-6319. [CrossRef]

68. Li, S.; Zhao, C.; Gou, H.; Li, H.; Li, Y.; Xiang, D. Synthesis and characterization of aniline-dimer-based electroactive benzoxazine and its polymer. RSC Adv. 2017, 7, 55796-55806. [CrossRef]

(C) 2020 by the authors. Licensee MDPI, Basel, Switzerland. This article is an open access article distributed under the terms and conditions of the Creative Commons Attribution (CC BY) license (http://creativecommons.org/licenses/by/4.0/). 